\title{
SKILLS AND HRD IN THE EMERGING GLOBAL MARKET PERSPECTIVE: A CASE OF INDIA
}

\author{
I.C.Awasthi*
}

\begin{abstract}
Skills are regarded an important growth driver in knowledge based globalised economy. In most of the developed nations and fast growing economies have very high proportion of skilled work force, while the skill levels among the Indian work force is abysmally low and probably among the lowest in the world. One of the reasons for the low skill trained manpower is terribly low institutional training capacity and the vocational education and training systems as being too supply driven and far-removed from market demand. India has distinct advantage of young age-population with declining dependency ratio which is termed as 'population dividend' while the industrialized nations have ageing population with rising dependency ratio. This precisely gives India an advantage with huge competitive edge internationally. While industrialized nations will be facing acute shortage of skills with increasing dependency ratio, India can harness this huge potential if skill development initiatives fructifies in right direction which will then be in real sense a 'population dividend'. If this opportunity is missed then it may well turn in to 'demographic nightmare'
\end{abstract}

The paper aims at examining the skill issues in the context of globalization and seeks to scrutinize how the skilling efforts have moved on to central stage in order to reap the benefits. The paper explores the theme both from the demand and supply perspectives in a complex yet exciting global environment.

Key words: human resource development, labour market, skill development, industrial restructuring, demographic dividend.

\section{INTRODUCTION}

Human Resource Development (HRD) is a process of preparing human resource for active participation in the social and economic development process. Active participation is primarily of two types:

First, availing the employment opportunities generated by the existing and emerging economic structure and technologies in the process of economic development and evolving new technologies and new economic systems to aid the process of economic development.

\footnotetext{
${ }^{*}$ Mr. Awasthi is Joint Director of Institute of Applied Manpower Research, Delhi.
} 
Second, there are three dimensions which have the potential to contribute to human resource development: Health and nutrition; social and economic equity; and education. Among these three dimensions education is the most important dimension of human resource development.

\section{ROLE OF EDUCATION AND SKILLS}

There are strong arguments, theoretically as well as empirically that strengthening education - particularly primary and secondary education - has enormous spill over beneficial effects to the society and industry (Blaug, 1966; Drez \& Sen, 1989; Schultz, 1960; World Bank, 1990). It enhances and improves productivity and flexibility, and increases mobility. Education provides the very foundation upon which further skill and acumen can be built upon.

Education is a major dimension of human resource development and has an innate relationship with labour market conditions, primarily, because education is viewed as a means of improving skills required by jobs thrown up in the labour market. Skills in relation to any job have two components: Generic skill and specific skill (Chandra, 1991). Generic skill is a cognitive and theoretical knowledge, which facilitates the process of learning to do a job, and provides a foundation for acquiring higher skill specific to the job. Specific skill, on the other hand, is technology specific. While generic skill can be expected to be stable over a long period of time; specific skill, being technology specific, is likely to change with the change in technology. Life span of a specific skill, therefore, is closely related to the productive life of any technology.

Another major distinction between generic and specific skill is that while generic skill can be acquired largely through formal education and training system; it is not always possible to acquire specific skill through formal education system, because of the very nature of the specific skill. In view of this, route to acquisition of specific skill are often mostly through on the job training and off the job formal/informal training.

Broad features of the skill spectrum in a dynamic and developing economy would be:

- Widening skill base;

- Learning to learn becomes a key factor for both the individuals and the economic enterprises level;

- Proportion of knowledge workers and demand for higher order generic skills increases;

- Compulsions to adjust to changing job requirements increases labour flexibility and demand for acquiring new skills; and

- Enterprises also tend to be dynamic in terms of technology adoption, improving organizational design, and enhancing productivity and quality standards. 
Skills reside in various categories or groups of human resource such as shop floor workers, supervisors, decision-makers, teachers and innovators. Training requirements of each category needs to be worked out by identifying existing and emerging functions and activities, projecting the kind of physical and mental base required and job specific proficiencies demanded in various tasks. For example, unskilled and semi-skilled workers are likely to carry out standardized tasks requiring routine operations, involving low/medium/high physical effort depending on technology in use but low mental effort. Formal educational attainment of secondary or even lower level may be adequate for them, while more training in know-how or techniques would be required on a continuing basis to adjust to changing work environment. In contrast, the innovator's tasks are non-standard, non-routine, low in physical effort but requiring high mental effort. Educational requirement for this category would be not only tertiary level but also post-graduate and possibly PhD. as well. Training requirement in highly specialized techniques is also extremely high for this category.

Human resource development, though recognized as one of the important objectives of economic growth, it did not receive adequate attention in the development agenda until the early 1970s. Growing disillusionment with emphasis on growth in the development agenda and the increasing realization that human resource development is a means as also the ultimate objective of development process brought HRD to the center stage of social and economic development process in the early 1990s. The success stories of ASEAN countries in particular, which have achieved remarkable economic progress through investment in human resource, have emphasized the need to dovetail HRD policy with the overall development process (Rao, 1995; World Bank, 1993). It is also increasingly being recognized now that HRD per se crucially dependent on the demand and supply forces which govern the labour market conditions (Amjad, 1987).

\section{DEMAND SIDE OF THE LABOUR MARKET}

Demand forces of the labour market can be traced to the nature of employment being generated. Employment generation in turn depends on variety of factors such as: Overall growth of economy and its sectoral pattern of distribution; labour absorptive capacity of the growth process; rate of growth of labour force; level and structure of investment and production; type of technology used; institutional mechanism for technology development; aggregate demand of goods and services and social, cultural traditions etc.

Inadequate attention to these factors and improper balancing to the effect of these forces has generated a variety of distortion in the demand forces governing the labour market among the developing countries. India is no exception in this regard. For instance, the traditional route to economic development followed by the developed nations is that development originated from agricultural sector, it passed through the manufacturing sector to ultimately end up in the services sector. In this route, 
due to primacy attached to industrialization and growth of manufacturing sector, organized sector dominated. In this route to development, employment generation resulted in jobs requiring more of cognitive skills. Forecasting of skill requirements and planning HRD was much easier because of the primacy assigned to formal education system. Development experiences of developing countries in the 1980s and 1990s, on the other hand, indicate that the route to development is totally different in these countries. In this route, while development originated in agricultural sector it passed through mostly the services sector. Only in some cases, services sector enterprises lead to the establishment of manufacturing. Many of the countries even built up a strong agricultural sector and a fairly supportive service sector at the neglect of manufacturing sector. This resulted in declining role of organized sector, which has been mostly compensated, by the increasing role of unorganized sector. This is because service sector and even the manufacturing segment, which emerged, have been mostly in the informal sector. Growth of informal sector has been observed to cause significant changes in the structure of employment. As a result, there has been overall deterioration of quality of employment. For instance, share of self-employment has been decreasing and that of casual employment increasing steadily and proportion of wage employment has been stagnating (Papola \& Sharma, 1996). Skill levels will be very low with very little cognitive skill. Productivity and quality standards also tend to be low resulting in low income and low investment. Of late, issue of social security for the unorganized sector is gaining currency that has wider social ramifications to the political economy. Second National Labour Commission (NLC, 2002) has reviewed the issues of social security measures for the unorganized sector and National Commission for Enterprises in the Unorganized Sector (NCEUS, 2006) has brought out important reports in this regard -- one on social security and another one on conditions of work and livelihood. Despite the facts that these are important initiatives for the cause of social security of the unorganized sector workers' yet it faces numerous implementation challenges ahead (Awasthi \& William, 2008). Eventually, this has come in the form of bill the "Unorganised Sector Workers' Social Security Act, $2008^{\prime \prime}$ but with much diluted version what was proposed by the Commission.

It must be emphasized here that if the process of employment and income generation is efficient and equitable then it affords better working and living conditions. On the other hand, if this process leads to labour market segmentation, crowding of occupations and other such labour market distortions, working and living conditions would naturally deteriorate. Likewise, higher the productivity and incomes the better will be the working and living conditions. Productivity and incomes, in turn, depend on the process of employment and income generation. If the process is not efficient and equitable, it will result in lower productivity and incomes and vice-versa. In the same vein, it may be argued that, sustained levels of higher productivity and incomes will eventually neutralize labour market distortions; and will result in efficient and equitable generation of employment and incomes (Sen, 1983; Todaro, 1985). 
Casualisation of employment is a disturbing feature, because evidence available indicates that it results in declining growth of productivity of labour along with rapid growth in employment. A situation with high rate of growth of employment associated with deceleration in the rate of growth of productivity is not a viable form of growth, as there will be difficulties in sustaining the observed high growth of employment in the urban areas in future (Deshpande, 1992).

There is another aspect of the above issue, which needs serious consideration. If the employment is casual and provides low income, then the group of persons depending on casual employment, because of irregular nature of association with any given job, and low economic status would have no opportunity in their lives for acquiring skills for further development. At the policy plane such situations raise issues of human resource development and productivity improvement.

Social problem of casualisation of employment results in the segregation of urban population into resident population and migrant population. The latter mostly comprises of casual workers residing in urban slums. Casualisation thus may ultimately lead to the emergence of slums where migrants get accommodated.

This structural change in the pattern of development as between the developing and developed countries has also altered the nature of employment generated among the developing countries. For example, in developing countries open unemployment is being gradually replaced by increasing under-employment. Developing countries are also experiencing increasing labour market segmentation. Segmented labour markets introduced distortions in factor markets, which ultimately resulted in discouraging of investments, and imbalanced pattern and pace of growth.

Regular employment based on wage/salary has also been declining in its place selfemployment has been increasing. Self-employment has also been generally in low investment, low productivity and low-income generating activities. The on-going structural process among the developing countries is creating further distortions in the demand forces in the labour markets. The compulsion to modernize and improve quality continuously necessitated continuous changes in the technology resulting in specific skill requirements of jobs in all the segments of the economy. Some of the emerging skill requirements are totally new alien to the labour market in these countries.

The emerging signals from demand, labour force thus pose many challenges to the human resource development. Primary challenge is to increase the productivity of the employment opportunities being generated. The next challenge is to limit casualisation and increase in the creation of regular wage/salary based employment opportunities. Another challenge is to create self-employment opportunities in high productive and high value added segments. 


\section{THE SUPPLY SIDE OF THE LABOUR MARKET}

Education and training systems in many of the developing countries are still following the colonial pattern prior to independence. It is being dominated by general education, which is not specific of any job. It is rigid and insensitive to the demand forces emanating from the labour markets. It follows a linear structure that has a little scope for diversification or deviation. It is mostly controlled by the government or the public sector, which makes it even more inflexible because of bureaucratic rigidity, inhibitions and insensitivities. Educated unemployment is increasing because of irrelevance of training system to the job specific skill needs. This has resulted in over capitalization of occupations, increasing use of practicals, irrelevance of formally trained people, and emergence of unscrupulous private training shops offering unsystematic training with profit as the primary motive is the other emerging issues. In the process, individuals need to acquire higher levels of skills to improve performance in labour market and it is increasingly becoming expensive and out of reach of workers in the middle income and lower income groups.

\section{Labour Market and HRD}

Some of the problem areas, which have a bearing on the tasks before educational planners, are indicated here.

Adverse skill structure vis-à-vis the requirement for optimal utilization of productive systems poses a major problem. For instance, there are shortages of some critical skill categories at various levels and surpluses in other skill categories.

Also, there are too many persons with non-technical skill base causing sheer wastage of human resource.

\section{(i) Mismatch and Misutilisation of Available Human Resource}

Mismatch occurs in two ways. First, there is a quantitative mismatch between the supply generated by the educational infrastructure and demand generated by the economy. This type of mismatch might result from inadequate planning and forecasting of requirements aggravated further by social preference for certain types of educational qualifications. Although supply and demand may match at the global level, shortages and surpluses could be experienced at disaggregated levels. The other type of mismatch is qualitative and is represented by the gap between facilities and the abilities available for making effective use, for instance, production systems and the R\&D institutions.

Misutilisation refers to a situation when the person whose knowledge and skills have been developed for a certain role is utilized in a job having different role and functions. Technically qualified persons ending up in general administrative functions are one example. Skilled persons performing semi-skilled jobs are another. 


\section{(ii) Inappropriate Structure of Formal Education}

Transition rates from primary to secondary level are small with the result that the general educational level of workforce is too low. The proportion of students going in for vocational training is even smaller since most students prefer the general academic stream with a view to going in for higher general education. As a result, at the tertiary level, enrolment in general courses (arts, humanities, etc.) is too high.

\section{(iii) Education System does not Emphasize Quality and Relevance}

Cognitive aspects of education are over emphasized at the expense of skill to apply knowledge. Reasons for this situation can be traced to inadequate laboratory facilities, inadequately trained teachers and weak industry-education linkages.

\section{(iv) Crucial Need for Training and Retraining}

Training is not recognized sufficiently nor to arrangements exists for imparting practical training during or after formal education.

On-the-job training in organizations is not a common feature partly because it is not recognized as important and partly due to cost considerations.

\section{(a) Teacher Shortages}

Severe and persistent shortages of professionally trained teachers and trainers have been observed. Relatively low status associated with the teaching profession has been a determining factor in meeting with teacher shortages.

\section{(b) Obsolescence and Short-term Inelasticity of Skills Resource}

Obsolescence of technologies renders skills obsolescent and irrelevant. However, skill constraints in the introduction of new technologies from the side of skill availability are of a short-term nature and can be overcome by retraining of workers. Retraining might become difficult when the general educational level of the workforce is low.

\section{IMPLICATIONS OF ECONOMIC RESTRUCTURING}

Economic restructuring results change in relative share between small, medium and large industries; changes in technology; changes in product mix; and changes in the mix of end-users as between domestic and export markets. Technological changes in particular will result in the following actions:

- Shedding outmoded technology.

- Greater mechanization and computerization.

- Reorganization of production activities.

- Diffusion of technology in the economy. 
- Building up capacity to acquire and utilize technology

Human capabilities are required to be developed to meet the challenges posed by these actions.

\section{(i) Operative Capability}

This covers production know-how, production management, production engineering, troubleshooting and maintenance.

\section{(ii) Acquisitive Capability}

The capability to acquire technologies depends on the ability to search for, assess and transfer technologies. Abilities for the construction of plants, installation and commissioning and managing are included.

\section{(iii)Adaptive Capability}

This relates to the ability to modify existing production process or product design so that the process is better adapted to local factors and the product reflects local market preferences.

\section{(iv) Innovative Capability}

This involves the ability to anticipate future demands and to develop new designs, processes and technologies. R\&D capabilities are at the heart of this capability.

\section{TECHNOLOGY CHANGE AND HRD}

In order to meet with the challenges of technology changes, HRD has to be re-oriented to make it relevant.

Reorientation of HRD should aim at the following:

- Accelerating economic development (within the framework of social and economic development).

- Supporting industrial restructuring particularly associated with changes in technology.

- Imparting education and training for generation of manpower equipped with relevant knowledge and skills for performing various functions needed by the economy.

- Supporting productivity enhancement of manpower and man-machine system; 
- Developing and maintaining quality and relevance of manpower in the face of technological changes, and combating obsolescence.

- Ensuring employment with attributes of good income, decent working conditions and prospects of all round growth of human potential.

- Establishing education and training infrastructure, resource systems and enabler groups in order that continued attention is paid to planning, analysis and development of human resources.

- Developing entrepreneurship and creativity.

- Evolving strategies for creating and sustaining demand for human resource development.

- Mobilizing resources for training effort.

Relevance implies a correspondence between the nature of skills required and the type of skills provided. Maintaining quality and relevance of training can be attempted through continuing education.

Continuing education programmes are:

- rooted in the technology-context of industry;

- relate to skill development needs of the individual for the present job or the immediate future responsibility;

- are different from initial educational programmes which are aimed primarily at developing generic capabilities and potential;

- meet diversified and specific needs in ever-shorter time frame

- require strategies different from those of initial education system, as the target group are mature are not available on whole-time basis, and are concerned with immediate and specific learning needs.

Establishing a system of continuing education would entail, amongst others,

- enlargement of the role of formal educational institutions so as to include therein imparting continuing education to working persons; and

- setting up of new organizational mechanisms for training including training organizations of industry associations, professional societies, etc. 


\section{EMERGING SCENARIO}

Education and training as a major dimension of human resource development will have an increasing role to play in the globalised milieu to produce relevant skills of higher quality capable of ensuring higher growth and higher productivity. This calls for certain micro policy interventions both on the demand side and supply side.

\section{(i) Demand Side Interventions}

The issues, which call for demand side interventions, are the following:

- Arresting and slowing down the process of casualisation of employment.

- Creation of employment in the productive and high value added jobs.

- Arresting the trends of increasing under-employment/disguised employment.

- Ensuring regional/sectoral equity in developing and improving technology.

- To ensure production of quality at competitive prices in the domestic and international markets.

- Reversing the trend of rural-urban migration for employment.

\section{(ii) Supply Side Interventions}

- Evolving flexible education and training systems to ensure quality and relevance

- Ensuring balance between cognitive aspects, manipulative aspects of education and training to improve the employability of skills.

- Establishing strong industry education/training sector linkages to facilitate continuous and relevant changes in the curriculum and training methods.

- To reduce mismatch and misutilisation of human resource by strengthening mechanisms for continuing education, apprenticeship training and on-the-job training.

- To attach prime importance to teacher training, training of trainers and improving working and living conditions of teachers and trainers.

- To ensure labour flexibility to adapt to rapid changes in technologies, organizational design and work ethics.

- Regulating and controlling an undesirable expansion in skill development shops.

Individual initiatives to acquire skill and productivity will not be adequate. State with dwindling resources and changing economic development priorities is unlikely to invest more on human resource development. Employers are yet to realize the role of HRD in increasing overall prosperity. 


\section{SKILLS IN THE EMERGING ECONOMY}

Skills are regarded an important growth driver in knowledge based globalised economy. Most of the developed nations and fast growing economies have very high proportion of skilled work force. For instance, proportion of trained youth in industrialized countries ranges between 60 to 96 per cent in the age group of 20-24 years. In Korea it is extraordinarily high at 96 per cent, 80 per cent in Japan, 75 percent in Germany and 68 percent in the United Kingdom. While the skill levels among the Indian work force is abysmally low and probably among the lowest in the world. About 80 per cent of new entrants to the workforce have no opportunity for skill training. Recent NSS (61 ${ }^{\text {st }}$ round) results show that only about 2 per cent youth (15-29 years) have received formal vocational training and another 8 per cent have received non-formal vocational training (Government of India, 2007-12).

A large proportion of young people enter in to world of work without any skills training and they are forced to enter in the informal economy at awfully low wages and precarious working and living conditions. One of the reasons for the low skill trained manpower is terribly low institutional training capacity and the vocational education and training systems as being too supply driven and far-removed from market demand (NCEUS, 2009). Yet, another reason is sole reliance upon few training courses with 2-3 years duration covering about 100 skills while in china there are over 4000 short duration modular courses providing skill training to relevant to market needs. Also, skill development system is non-responsive to labour market needs and there are mismatches on quantitative and qualitative counts both from demand and supply sides. This has severe implications to the productivity (Government of India, 2007-12).

The existing training capacity is only 3.1 million per annum as against 12.8 million per annum new entrants to the workforce. In a way low skill profile among the workforce has direct manifestation on productivity and growth. The unorganized sector which constitutes about 93 per cent of workforce does not have any structural skills acquiring route and skill formation takes place within the sector through informal means. Only 2.5 per cent of the total unorganised sector workforce had formal training and 12.5 per cent had non-formal training while in the organized sector this proportion is 11 per cent and 10.4 per cent respectively (NCEUS, 2009). Government interventions through programme approach imparting training to this sector have only helped to minuscule level. The challenges to providing skill training to informal sector are enormous in view of its complexity and heterogeneity. In this regard National Commission for Enterprises in the Unorganised Sector has provided comprehensive recommendations for building a skill development and training system (NCEUS, 2009).

In view of this, Eleventh Plan has launched Skill Development Mission in order to enhancing training opportunities of new entrants to the labour force with particular emphasis on the twenty high growth high employment sectors. In this regard the 
Prime Minister's National Council on Skill Development (NCSD) has been set up for providing vision and giving broad policy directions. In order to support the NCSD and coordinating with different government departments in skill development initiatives National Skill Development Coordination Board (NSDCB) has been set up in the Planning Commission under the chairmanship of Deputy Chairman.

In order to support and expand skill development initiatives in the private sector, National Skill Development Corporation (NSDC) has been set up under the Ministry of Finance and NSDC will provide financial support to private sector initiatives in skill development.

India has distinct advantage of young age-population with declining dependency ratio which is termed as 'population dividend' while the industrialized nations have ageing population with rising dependency ratio. This precisely gives India an advantage with huge competitive edge internationally. While industrialized nations will be facing acute shortage of skills with increasing dependency ratio, India can harness this huge potential if skill development initiatives fructifies in right direction which will then be in real sense a 'population dividend'. If this opportunity is missed then it may well turn in to 'demographic nightmare'.

NCSD has outlined the vision, strategy and a set of core principles for developing skills in India. It is envisaged that 500 million people will be trained by the year 2022 . However, there are many hiccups as how this huge skill pool will be created in view of appallingly low level of skill training ( 2 per cent workforce has skill training at present), which is essential order to sustain a high level of economic growth.

\section{WAY AHEAD}

Skill development is imperative necessity in every production process (goods or services) in both within the organized and unorganized sector. Employment in the organized sector in any case is minuscule (7-8 per cent) and future employment growth rest on the unorganized or informal sector and there is a need for interventions both from demand and supply sides in order to make employment productive or efficient. These include skill development, technology improvement, product diversification, regulatory framework and social protection etc. Training and skill development needs in this sector are more urgent. It is also imperative necessity to manage and sustain higher rate of growth.

There is a need for integration (horizontal and vertical) of these programmes and to be made more relevant to the market needs. The whole concept of skill needs to be construed in the context of dynamic framework. Skills are becoming increasingly redundant and how fast newer technologies can be internalized depends on the skill level of workforce. There has been an uncertainty in the demand for skills and as a 
result institutions face pressures to increase their flexibility to respond changing needs. Continuous up gradation of skills is therefore paramount necessity. Unless numerous technical and vocational courses are qualitatively improved to make them marketable, these would continue to become less relevant to the needs of market.

Efforts to widening skill base without any evaluation and impact assessment on regular basis, its efficacy remains largely unknown. In technical courses like industrial training institutes (ITIs) and Polytechnics suffer from declining intake, obsolete trades, poor infrastructure and weak industry- education linkages. How these numerous skill trade programmes can be made more effective and efficient to respond the needs of changing economic environment still remains a major problem (Awasthi et. al., 2006).

In order to meet the requirement of a large number of learners (school graduates and school leavers), a variety of vocational courses will be required. These courses would need to be designed in relation to local needs and provide competencies, through full time and/or part time programmes, which enable a person to perform various production functions. The arrangements for training will need to be flexible, preferably in modular form, so that training facilities can be availed of conveniently (NCERT, 2001).

The challenges of skill development are enormous in a globalised economic environment and there are number of issues that need to be addressed urgently. Some of the issues have been flagged off by the Institute of Applied Manpower Research in recent international policy exchange workshop (IAMR, 2010).

Despite the fact that India has one of the largest pools of technical and scientific talent in the world its inventive capacity is abysmally low, which is critical from the standpoint of long-term growth. Basu (2008) informs that our performance on intellectual property rights has been dismal. The China which has poor record in its inventive capacity till recently has become one of the major countries in creating ideas in recent years. Clearly, there is a need to learn the lessons from the Chinese experience and also to unlearn from our own.

\section{References}

Amjad, R. (1987). Human resource development: The Asian experience in employment and manpower planning - An overview. In Amjad, Rashid (Ed.), Human resource planning - The Asian experience. ILO/ARTEP, New Delhi.

Awasthi, I.C. \& Swamy, K.V. (2006). Education and employment market: A case study of Krishna district. Journal of Adult Education and Extension, 2(2), 47-80. 
Awasthi, I.C. \&. Wordsworth, W. A.P. (2008). The unorganized sector workers' social security bill, 2007: Implementation challenges. Institute of Applied Manpower Research, Policy Brief 1/2008.

Basu, K. (2008, March 16). Why India needs to possess? Hindustan Times.

Blaug, M. (1966). Economic interpretation of the private demand for education. Economica. New Series, 33 (130), 166-182

Chandra, A. (1991). Policies and planning for human resource development for industries. UNESCAP, Bangkok (mimeo).

Deshpande, L.K. (1992). The Bombay labour market, Bombay: Bombay University Department of Economics. (mimeo).

Drez, J. \& Sen, A. (1989). Hunger and public action. Oxford: Clerendon Press.

Government of India (2008). Eleventh five year plan 2007-12 Vol. I, Chapter 5. New Delhi.

Institute of Applied Manpower Research (2010). The challenges facing skill development in India: An issue paper, prepared for the international workshop on skill development: policy learning and exchange, May 6-7, 2010, New Delhi.

Report of the National Commission on Labour (2002). Vol.I, (Parts I \& II), New Delhi.

National Commission for Enterprises in the Unorganised Sector (2006). Report on social security for unorganised workers, New Delhi.

National Commission for Enterprises in the Unorganised Sector (2009). Skill formation and employment assurance in the unorganised sector, New Delhi.

National Council of Educational Research and Training (NCERT) (2001). Report of expert group vocationalisation of education at the school stage, New Delhi.

Papola, T.S. \& Sharma, A.N. (1996). Structural adjustment, poverty, employment and safety nets: The Indian experience. Indian Journal of Labour Economics, 39, 591623.

Rao, C.H. Hanumantha (1995). Attack on poverty and deprivation: Role of structural change and structural adjustment. Indian Journal of Labour Economics, 38 (1), 11-22.

Schultz, T.W. (1960). Capital formation by education. Journal of Political Economy, 68, 571-583

Sen, A. (1983). Development: Which way now? The Economic Journal, 93 (372), 745-762.

Todaro, M. P. (1985). Economic development in the third world. New Delhi: Orient Longman.

World Bank (1993). The East Asian miracle: Economic growth and public policy, Oxford University Press. 